\title{
DEVELOPMENT OF CURRICULUM OF HIGHER EDUCATION (3 COUNTRIES)
}

\author{
Andria Pragholapati \\ Postgraduate School, Curriculum Development, Indonesian University of Education
}

\begin{abstract}
The curriculum is one component that has a fairly strategic role in the education system both nationally. The higher education curriculum is a set of plans and arrangements regarding the objectives, content, and teaching materials and ways used as guidelines for organizing learning activities to achieve higher education goals. Different education systems in each country are important ingredients in the key to the success of education in a country. One country that competes with Indonesia is Thailand, Malaysia, and Singapore.
\end{abstract}

\section{INTRODUCTION}

The curriculum is one component that has a fairly strategic role in the education system both nationally. The higher education curriculum is a set of plans and arrangements regarding the objectives, content, and teaching materials and ways used as guidelines for organizing learning activities to achieve higher education goals (DIKTI Law No.12, 2012). Based on the definition of education, it is stated that education is a conscious conscious effort. Educational planning will be contained in the curriculum as a path or path in running the wheels of education in order to achieve educational goals.

The curriculum has two meanings. First as a number of subjects that must be studied by students. Second a special learning program. In the curriculum, there are a set of subjects that must be taught at each level of education. Where each subject has its own curriculum. The curriculum of each subject is related to the competency that must be achieved in each subject so that the hours of study are also regulated in it.

The curriculum contained in the education system in each country has its own style based on the national education goals of a country. So as to understand the education system and curriculum of another country against the domestic curriculum can also be obtained from comparative education studies or educational comparisons. Comparative Study of Education or Comparative Education is an effort to compare two different education systems both between regions and between countries, education comparison emphasizes more on the practical side, namely the activity of comparing two different education systems.

Different education systems in each country are important ingredients in the key to the success of education in a country. One country that competes with Indonesia is Thailand, Malaysia, and Singapore. 


\section{ANALISIS PENULIS}

Singapura merupakan salah satu negara maju di ASEAN. Begitu pula dengan pendidikan yang diterapkan di Singapura juga memiliki sistem yang maju. Pendidikan di Singapura dibagi menjadi lima jenjang, jenjang pertama adalah Kindergarten School atau di Indonesia setara dengan Taman Kanak -Kanak (TK), jenjang selanjutnya yaitu Primary School atau setara dengan Sekolah Dasar (SD), jenjang ketiga yaitu Secondary School atau setara dengan gabungan Sekolah Menengah Pertama (SMP) dan Sekolah Menengah Atas (SMA). Jenjang keempat yaitu Junior College atau jenjang persiapan menuju universitas dan jenjang terakhir adalah University atau setara dengan Universitas.

Sistem pendidikan Singapura bertujuan untuk menyediakan pengetahuan dasar dan agama bagi murid-murid. Untuk menyatukan keberagaman karasteristik perbedaan ras dan budaya di Singapura, keberagaman bahasa, setiap siswa belajar Bahasa Inggris sebagai bahasa keseharian. Siswa juga belajar Bahasa Ibu mereka (China, Malaysia dan Tamil/Thailand) untuk membantu mereka mempertahankan identitas, budaya, warisan, dan nilai-nilai bangsa.

Pendidikan vokasi di Thailand menerapkan lama belajar 5 (lima) tahun dimana tamatannya setara dengan lulusan diploma 2 tahun di Indonesia, sementara pendidikan vokasi di Indonesia menerapkan lama belajar 3 (tiga) tahun. Oleh karena itu, di Thailand tidak dikenal perguruan tinggi

Politeknik seperti di Indonesia. Politeknik di Thailand berperan sebagai institusi 'long-life learning' atau institusi yang memberikan sertifikat bagi keahlian tertentu, seperti mengelas, menjahit dll. Thailand juga menerapkan wajib belajar 9 tahun, seperti di Indonesia, namun pendidikan gratis diberikan sampai tamat sekolah menengah atas.

\section{KESIMPULAN}

Pendidikan formal di Singapura dimulai dari jenjang Kindergarten School sampai jenjang University. Untuk memasuki Pendidikan Tinggi disyaratkan bagi siswa untuk mendapatkan sertifikat tingkat A yang diperoleh dengan mengikuti ujian sertifikasi tingkat A di akhir Pendidikan Pasca-Menengah dengan pilihan Junior Collage selama 2 tahun dan Central Institute selama 3 tahun, keduanya hanyamenerima siswa yang mendapatkan sertifikat $O$. Terdapat pula Institut PendidikanTeknik (ITE) yang menerima siswa dengan sertifikat $\mathrm{O}$ dan $\mathrm{N}$, memberikan pelatihan selama 2 tahun, sedang lulusannya memperoleh sertifikat ITE danDiploma Insinyur Teknologi Teknik Mesin (TED) selain juga dapat melanjutkanke Politeknik atau Universitas. Adapun Politeknik menerima siswa dengansertifikat tingkat $\mathrm{O}$, tingkat $\mathrm{A}$, dan nilai ITE. Lulusannya dapat segera memasukidunia kerja dan sebagiannya melanjutkan ke Pendidikan Tinggi (Universitas). Ada banyak faktor yang menyebabkan Singapura berhasil mendapatkan predikat sebagai negara dengan sistem pendidikan terbaik se-ASEAN, yaitu faktor-faktor ketersediaan fasilitas, faktor biaya sekolah yang terjangkau, dan faktor pendidik.

Sistem pendidikan Negara Malaysia bermula dari Pra-Pendidikan Dasar, Pendidikan Dasar 6 tahun dengan pembedaan antara sekolah anak Melayu dan sekolah anak etnis Cina dan Tamil 
(Sekolah Tipe Nasional), tambahan 1 tahun kelas transisiuntuk Sekolah Tipe Nasional untuk penguasaan bahasa Melayu, Pendidikan Menengah Bawah 3 tahun, Menengah Atas 2 tahun dengan pilihan jalur Akademisdan Teknik-Kejuruan, Pasca-Pendidikan Menengah 1-2 tahun untuk persiapan memasuki jenjang Pendidikan Tinggi, dan terakhir adalah Pendidikan Tinggi dengan berbagai sertifikasinya.

\section{REFERENCES}

Ade, M.S., Tjutju, Pragholapati, A., 2016. GAMBARAN KUALITAS HIDUP PADA LANSIA DI BALAI PERLINDUNGAN SOSIAL TRESNA WERDHA CIPARAY BANDUNG TAHUN 2016.

http://ejurnal.stikesbhaktikencana.ac.id/file.php?file=preview_mahasiswa\&id=532\&cd=0b2173f f6ad6a6fb09c95f6d50001df6\&name=JURNAL\%20SAKINAH\%202016.pdf.

Andria Pragholapati, M.L., 2017. HUBUNGAN MASALAH KESEHATAN JIWA DENGAN STRATEGI KOPING SESEORANG YANG MENGALAMI PERCERAIAN DI KOTA BANDUNG, in: Seminar Nasional Dan Workshop Keperawatan " Penguatan Profesi Keperawatan Dalam Peningkatan Pelayanan Keperawatan" Continuum of Care Dari Ketergantungan Menuju Kemandirian Hidup Yang Berkualitas. ISBN: 978-602-14422-8-9.

Andria Pragholapati, R., 2018. DEVELOPMENT OF THE INDONESIAN NATIONAL QUALIFICATIONS FRAMEWORK FOR NURSING CURRICULUM, in: International Conference on Education and Regional Development 3rd (ICERD) 2018 "Curriculum for Generation of Discruptive and 4th Industry Revolution Era." p. 44.

Andria Pragholapati, R.M., 2017. HUBUNGAN BULLYING DENGAN KEMAMPUAN SOSIAL PADA REMAJA DI SMK MVP KOTA BANDUNG TAHUN 2017, in: Konferensi Nasional Keperawatan Kesehatan Jiwa XIV Di Kalimantan Selatan Tahun 2017.

Andria Pragholapati, T., 2018. HUBUNGAN PENGGUNAAN SMARTPHONE DENGAN KUALITAS TIDUR PADA REMAJA DI SMK X BANDUNG, in: Konferensi Nasional Keperawatan Kesehatan Jiwa XV Di Hotel Four Point By Sheraton Makassar Sulawesi Selatan. pp. 1-7.

Ardiana, F., Nurlianawati, L., Pragholapati, A., 2016. Gambaran Fungsi Kognitif Pada Lanjut Usia (Lansia) Di Panti Jompo Muhammadiyah dan Yayasan Pondok Lansia Tulus kasih.

Ariani, A., Pragholapati, A., Pratama, A.S., 2020. Information Communication Technology (ICT) In Midwifery Education: A Review of the Literature, in: The 3rd International Seminar on Global Health (ISGH) "Technology Transformation in Health Care for Better Life" Bandung, West Java, Indonesia. http://repository2.stikesayani.ac.id/index.php/isgh3/article/view/352, pp. 66-69.

Ismawati, Y., Pragholapati, A., 2020. KEJADIAN GASTRITIS DI DESA CINUNUK WILAYAH KERJA PUSKESMAS CINUNUK KABUPATEN BANDUNG. 
Ismawati, Y., Sumbara, Pragholapati, A., 2018. HUBUNGAN POLA MAKAN DENGAN KEJADIAN GASTRITIS DI DESA CINUNUK WILAYAH KERJA PUSKESMAS CINUNUK KABUPATEN BANDUNG.

Pragholapati, A., 2020. Self-Efficacy Of Nurses During The Pandemic Covid-19.

Pragholapati, A., 2020. COVID-19 IMPACT ON STUDENTS. osf.io.

Pragholapati, A., 2020. RESILIENSI PADA KONDISI WABAH COVID-19.

Pragholapati, A., 2020. STRES KERJA PERAWAT YANG BEKERJA DI UNIT GAWAT DARURAT (UGD) RUMAH SAKIT AL ISLAM (RSAI) BANDUNG.

Pragholapati, A., 2020. MOTIVASI KERJA PERAWAT DI RUANG RAWAT INAP RSUD MAJALAYA KABUPATEN BANDUNG.

Pragholapati, A., 2020. MENTAL HEALTH IN PANDEMIC COVID-19.

Pragholapati, A., 2020. RESILIENSI PERAWAT YANG BEKERJA DI UNIT GAWAT DARURAT (UGD) RUMAH SAKIT AL ISLAM (RSAI) BANDUNG.

Pragholapati, A., 2020. NEW NORMAL “INDONESIA” AFTER COVID-19 PANDEMIC.

Pragholapati, A., 2019. THE EFFECT OF BRAIN GYM TO THE LEVEL OF DEPRESSION IN GERIATRIC AT BALAI PERLINDUNGAN SOSIAL TRESNA WERDHA CIPARAY BANDUNG. J. Sk. Keperawatan 5, 128-146.

Pragholapati, A., Munawaroh, F., 2020. RESILIENSI PADA LANSIA. J. Surya Muda 2, 1-8.

Pragholapati, A., Ulfitri, W., 2019. Gambaran Mekanisme Coping pada Mahasiswa Program Studi Sarjana Keperawatan Tingkat IV yang Sedang Menghadapi Tugas Akhir di Sekolah Tinggi Ilmu Kesehatan X Bandung. Humanit. J. Psikol. 3, 115-126.

Prasetyo M, D., Nurlianawati, L., Pragholapati, A., 2017. GAMBARAN TINGKAT KECEMASAN PADA PASIEN PRE OPERASI FIBROADENOMA MAMMAE DI RUANG GUNTUR RUMAH SAKIT TK II DUSTIRA CIMAHI TAHUN 2017. http://ejurnal.stikesbhaktikencana.ac.id/mahasiswa.php?detail=mahasiswa\&id ....

Rahmawati, S.D., Mulyati, T., Pragholapati, A., 2015. HUBUNGAN BODY IMAGE DENGAN POLA DIET PADA REMAJA PUTRI DI SMAN 24 BANDUNG TAHUN 2015. http://ejurnal.stikesbhaktikencana.ac.id/file.php?file=preview_mahasiswa\&id ....

Rosmala, I., Jundiah, S., Pragholapati, A., 2017. TINGKAT KECEMASAN PADA KELUARGA PASIEN DI RUANG ICU RSUD MAJALAYA KABUPATEN BANDUNG TAHUN 2017. http://ejurnal.stikesbhaktikencana.ac.id/file.php?file=preview_mahasiswa\&id=517\&cd=0b2173f f6ad6a6fb09c95f6d50001df6\&name=Jurnal\%20Imas\%20Rosmala\%202017.pdf.

Septriani, D., Sari, Y.R., Pragholapati, A., 2019. The Relationship of Social Support With the Anxiety Level of Parents of Children with Thalassemia of Pre-School Age that Works in the 
Activities of Blood Transfusion in Hospital "X" Bandung, in: The 2nd Bandung International Conference on Collaborative Health Research Research. Prama Grand Preanger Hotel Bandung, West Java, Indonesia 7th - 8th of October 2019. p. 12.

Virgona, A., Pragholapati, A., 2019. Enhancing Critical Thinking Skills in Nursing Higher Education in Preparation for the Industrial Revolution 4.0: Literature Review, in: The 3rd International Seminar on Global Health (ISGH) "Technology Transformation in Health Care for Better Life" Bandung, West Java, Indonesia.

Portal Rasmi Kementerian Pendidikan Malaysia. Diakses dari https://moe.gov.my/index.php/my/kurikulum

Yunardi. (2014). Sistem Pendidikan di Thailand. Diakses dari http://www.atdikbudbangkok.org/Sistem-Pendidikan-di-Thailand.pdf

http://unesdoc.unesco.org/images/0021/002152/215280E.pdf

http://unesdoc.unesco.org/images/0015/001524/152453eo.pdf

https://www.icnvoicetolead.com/wpcontent/uploads/2017/04/ICN_AVoiceToLead_guidancePack-9.pdf

Pragholapati, A. (2020). Depression in Someone Who Has Divorce.

Pragholapati, A. (2020). Anxiety in Someone Who Has Divorce.

Pragholapati, A. (2020). The Role of Nurses in Divorce.

Pragholapati, A. (2020). Marriage and Divorce.

Pragholapati, A. (2020). Mental Health Issues Someone Who Has Divorce.

Pragholapati, A. (2020). Coping Strategies for Someone Divorced.

Pragholapati, A., \& Indonesia, P. RESILIENSI PADA KONDISI WABAH COVID-19.

Pragholapati, A. (2020). RESILIENSI PERAWAT YANG BEKERJA DI UNIT GAWAT DARURAT (UGD) RUMAH SAKIT AL ISLAM (RSAI) BANDUNG.

Pragholapati, A. (2020). NEW NORMAL “INDONESIA” AFTER COVID-19 PANDEMIC.

Pragholapati, A. (2020). STRES KERJA PERAWAT YANG BEKERJA DI UNIT GAWAT DARURAT (UGD) RUMAH SAKIT AL ISLAM (RSAI) BANDUNG. 
Pragholapati, A. (2020). MOTIVASI KERJA PERAWAT DI RUANG RAWAT INAP RSUD MAJALAYA KABUPATEN BANDUNG.

Pragholapati, A. (2020). MENTAL HEALTH IN PANDEMIC COVID-19. Available at SSRN 3596311. 